trends, the rise of evidence-based clinical practice is potentially at odds with rights-based law. Medicine places primacy on outcomes, including broad concepts such as quality of life and consumer and carer satisfaction. A growing empirically based critique of mental health law may be anticipated, moving beyond 1970s concerns about 'rotting with your rights on' to questions about the relative therapeutic benefits of different legislative approaches. This would represent a hybridisation of medical and legal thinking, potentially with a common ethical foundation.

Another interesting trend is the substantial investment made in quality improvement methodologies in recent decades, most notably service and practice accreditation schemes, which are common in Australia. These provide a compelling alternative to legislative mandating of minimum standards of care in MHAs. In this model, mental health law and accreditation schemes are part of a portfolio of safeguards, rather than mere separate entities, and the protections in a given jurisdiction would be assessed accordingly.

\section{References}

Carney, T. (2007) Mental health legislation in the Commonwealth. Current Opinion in Psychiatry, 20, 482-485.

Gray, J. E., McSherry, B. M., O'Reilly, R. L., et al (2010) Australian and Canadian mental health Acts compared. Australian and New Zealand Journal of Psychiatry, 44, 1126-1131.

Kisely, S. R., Campbell, L. A. \& Preston, N. J. (2011) Compulsory community and involuntary outpatient treatment for people with severe mental disorders. Cochrane Database of Systematic Reviews, 16(2), CD004408

McSherry, B. \& Wilson, K. (2011) Detention and treatment down under: human rights and mental health laws in Australia and New Zealand. Medical Law Review, 19, 548-580.

National Working Group on Mental Health Policy (1994) Model Mental Health Legislation: Report to the Australian Health Ministers' Advisory Council National Working Group on Mental Health. University of Newcastle, Centre for Health Law, Ethics and Policy.

Venkataraman, P. \& McSherry, B. (2010) Incorporating carers' rights in mental health legislation. Journal of Law and Medicine, 17 481-486.
MENTAL HEALTHLAW PROFILE

\title{
Dangerousness and mental health treatment: civil commitment in the USA
}

\author{
Michael J. Vitacco ${ }^{1,2}$ and James Degroot ${ }^{1,3}$
}

'Assistant Professor, Georgia Regents University, Georgia, USA email mvitacco@gru.edu 2East Central Regional Hospital, Augusta, Georgia, USA 3Director of Mental Health, Georgia Department of Corrections, Forsyth, Georgia USA
Civil commitment standards in the USA have undergone dramatic changes over the past 50 years. The relevant statutes have largely focused on treatment, but how this treatment has been administered and the placement of individuals undergoing commitment have been dynamic. There have also been changes in commitment as it relates to sexual offenders and individuals deemed not competent to proceed to trial. As legislatures strive to find a balance between mandated treatment and civil liberties, changing standards of commitment provide opportunities for scholarship and research.

Civil commitment, a mechanism for mandating treatment due to dangerousness, is one of the most contentious areas of mental health law. In the USA the contentiousness is related to the often precarious balance of protecting the civil liberties of an individual with a mental illness versus protecting society from potentially violent individuals. The government has a right under parens patriae to protect individuals who are unable to care for themselves or are a danger to themselves; in addition, the government has authority under police power to protect society. When properly done, these two apparently orthogonal ideas can work harmoniously, and both the rights of the individual and the protection of society will be safeguarded. This paper reviews several issues related to the civil commitment process in the USA, including laws and due process, recent developments in civil commitment and treatment issues in civil commitment.

\section{Civil commitment law, dangerousness and due process}

Civil commitment laws have recently undergone greater scrutiny as they are viewed as a potential prophylactic to violence in the wake of mass killings at Virginia Tech University in Blacksburg, Virginia, a political event in Tucson, Arizona, and a shooting at an elementary school in Newtown, Connecticut. This was especially evident in the case of Seung-Hui Cho, who underwent a civil commitment hearing prior to the murders of 32 people at Virginia Tech. During that hearing it was decided that Cho did not meet the criteria for civil commitment because he was deemed not 'imminently dangerous' (Pfeffer, 2008). Likewise, there is evidence that Jared Lee Loughner, who killed 6 and injured 14 more in Tucson, Arizona, 
has a significant mental illness requiring treatment (Winter, 2012). Unfortunately, these events have continued to perpetuate negative stereotypes, although the actual relationship between mental illness and violence is relatively slight (Elbogen \& Johnson, 2009).

The early laws authorising civil commitment were not predicated on dangerousness; instead, states could commit people to an in-patient facility for treatment if they had a mental illness and were good candidates for in-patient care. Such commitments generally relied on the opinion of one mental health professional. Behaviours that would qualify an individual for commitment included mild forms of mental illness and even behaviours that might be considered only annoyances. With the deinstitutionalisation of the 1960s, civil commitment laws began relying on imminent dangerousness. Imminent dangerousness standards are geared towards the use of governmental powers to protect the public from dangerous individuals with mental illness, but have been criticised as unnecessarily narrow, in that few individuals (only the most impaired) qualify for treatment under them.

Early commitment laws involved few due process rights. Individuals did not have a right to crossexamine witnesses, present their own rebuttal witnesses or petition for release. In the landmark case of Lessard v. Schmidt, Alberta Lessard was civilly committed because of her 'mental illness'. Lessard, on her own accord, hired an attorney and argued that allowing for detention up to 145 days without a hearing was a violation of her civil liberties. In the United States District Court for Eastern Wisconsin, Lessard prevailed on numerous grounds, including that individuals undergoing civil commitment proceedings should be afforded basic due process rights and that in order for the state to prevail in a civil commitment hearing there needed to be a finding of dangerousness.

Although limited to Wisconsin, other states soon attached due process rights to civil commitment proceedings. Notably, the Supreme Court of the United States in Baxstrom v. R.E. Herold ruled that prisoners in the New York correctional system referred for commitment at the time of their discharge were entitled to a jury hearing to protect their due process rights. The case of O'Connor $v$. Donaldson exemplified the rights of the individual as the Supreme Court ruled that a hospital was not allowed to detain a non-dangerous person with a mental illness who could survive independently or with available help. This decision underscored the notion of least restrictive placement, especially with an individual who was deemed not dangerous to self or others. Finally, in Addington v. Texas, the United States Supreme Court spoke directly to the issue of burden of proof and evidentiary standards related to civil commitment and proposed that the minimum evidentiary requirement for commitment was 'clear and convincing evidence'; however, states would be free to adopt the more stringent 'beyond a reasonable doubt' criterion.

\section{Recent changes in the construct of civil commitment}

In recent years, civil commitment standards again have changed as two classes of individuals have garnered attention: individuals committed after a legal finding of not competent to stand trial and sex offenders civilly committed after serving prison sentences but still deemed to be a danger to others. In Kansas v. Hendricks, the United States Supreme Court held that a Kansas law authorising the civil commitment of sex offenders, for the ostensible purpose of providing them with treatment in order to prevent future sex offences, was constitutional. These civil commitment laws, now enacted in several states, are typically referred to as 'sexually violent persons' or 'sexually violent predator' (SVP) acts and allow the state to commit individuals, providing the individual is judged to remain sexually dangerous. Three things are noteworthy regarding these laws. First, they are highly controversial, with arguments about their constitutionality and the high cost to taxpayers. Second, as elucidated in Kansas v. Crane, states have wide latitude in defining mental illness under these laws. Third, the concept of dangerousness is not narrowly construed, as it has expanded in terms of both imminence and behaviour.

States have needed to develop innovative strategies to manage individuals deemed not competent to proceed to trial and committed as in-patients due to dangerousness. Rooted in the landmark case of Jackson $v$. Indiana, which placed limits on the time allowed for the commitment of an incompetent defendant, states have routinely struggled with individuals committed for competency restoration. This is especially true if the individual is found not competent to proceed to trial and not likely to be restored. Unfortunately, the criteria elucidated in the Jackson case are often not employed (Hoge, 2010). Legislatures must continue to balance the rights of the individual found not competent to proceed to trial and community safety.

\section{Civil commitment and treatment}

The purpose of civil commitment is to provide treatment, with the goal of reducing risk, whether that involves risk to self, violence to others, or recidivism specific to sexual offences. Legislatures have several options for administering commitment laws. For example, the creation of out-patient civil commitment laws represents a vital paradigm shift in mandated treatment. Out-patient commitment has the dual advantage of protecting individual liberties in the context of mandated treatment (Erickson et al, 2005). By providing an alternative to in-patient commitment, states save money, treat persistent mental illnesses with community-based programmes and minimise problems associated with the non-treatment of mental illness. A prime example of the move to out-patient commitment in New York occurred after an individual with a chronic mental illness pushed Kendra Webdale in front of a subway train, leading to her death. This 
led to the creation of Kendra's law (Appelbaum, 2005).

\section{Conclusions}

Civil commitment laws continue to evolve, with changing standards in mental healthcare often spurred by tragic events that bring the nexus between violence and mental illness into our living rooms. There appear to be two certainties regarding civil commitment standards in the USA. First, commitment laws will remain controversial and contentious as states try to strike a balance between rights and safeguards. Second, there are likely to be further changes in civil commitment standards with the advent of new treatments and, unfortunately, further acts of high-profile violence.

\section{References}

Appelbaum, P. (2005) Assessing Kendra's law: five years of outpatient commitment in New York. Law and Psychiatry, 56, 791-792.

Elbogen, E. B. \& Johnson, S. C. (2009) The intricate link between violence and mental disorder. Results from the National Epidemiologic Survey on Alcohol and Related Conditions. Archives of General Psychiatry, 66, 152-161.
Erickson, S., Vitacco, M. \& VanRybroek, G. (2005) Beyond overt violence: Wisconsin's progressive civil commitment statute as a marker of a new era in mental health law. Marquette Law Review, $89,359$.

Hoge, S. (2010) Commentary. Resistance to Jackson v. Indiana - civil commitment of defendants who cannot be restored to competence. Journal of the American Academy of Psychiatry and the Law, 38, 359-364.

Pfeffer, A. (2008) 'Imminent danger' and inconsistency: the need for national reform of the 'imminent danger' standard for involuntary civil commitment in the wake of the Virginia Tech tragedy. Cardozo Law Review, 30, 277-315.

Winter, M. (2012) Loughner loses appeal to halt forced medication. USA Today, 5 March.

Addington v. Texas, 441, U.S. 418 (1979)

Baxstrom v. R. E. Herold, 383 U.S. 107 (1966)

Jackson v. Indiana, 406 U.S. 715 (1972)

Kansas v. Crane, 534 U.S. 407 (2002)

Kansas v. Hendricks, 521 U.S. 346 (1997)

Lessard v. Schmidt, 349 F. Supp. 1078 (E.D. Wis. 1972)

O'Connor v. Donaldson, 422 U.S. 563 (1975)

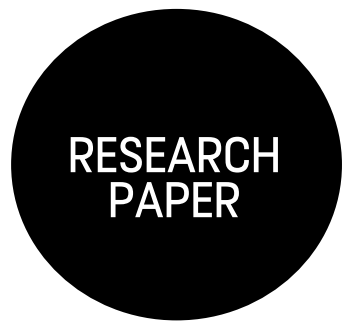

\title{
The cross-cultural sensitivity of the Strengths and Difficulties Questionnaire (SDQ): a comparative analysis of Gujarati and British children
}

\author{
Manasi Kumar ${ }^{1}$ PhD CPsychol and Peter Fonagy PhD FBA ${ }^{2}$
}

${ }^{1}$ Lecturer, Department of Psychiatry, University of Nairobi, Kenya, email manni_3in@ hotmail.com

${ }^{2}$ Freud Memorial Professor, Research Department of Clinical, Educational and Health Psychology, University College London, London, UK, email p.fonagy@ucl.ac.uk

The authors would like to acknowledge the help of Ms Kathryn Newberg with the preparation of this paper.
The purpose of this study was to investigate whether the Strengths and Difficulties Questionnaire (SDQ) may be considered a reliable measure of child behaviour, social functioning and adjustment in an Indian Gujarati context. The sample comprised 351 children who were classified as coming from a 'poverty' or 'non-poverty' background. The means and standard deviations for the SDQ total and five behavioural scales, as rated by children themselves, were first calculated for the entire Gujarati sample, then for the poverty and non-poverty subgroups. The SDQ did prove to be an appropriate measure for behavioural assessment. Its cross-cultural sensitivity was ascertained by comparing it against a British normative population. Small effect sizes were seen in the Emotional subscale scores and scores for total difficulties, and medium and large effect sizes on the Prosocial and Peer subscales, respectively, with greater difficulties experienced by the Indian Gujarati sample than their British counterparts.
The main aim of the present study was to find the prevalence and distribution of behavioural problems using the Strengths and Difficulties Questionnaire (SDQ; Goodman, 1997) in a sample of school-aged Gujarati children in order to identify socio-emotional patterns and adjustment issues. Additionally, a cross-cultural analysis compared the Gujarati sample's scores with those from a British normative sample of children.

The SDQ has subscales (with five items per scale) covering conduct problems, hyperactivity, emotional problems, peer and prosocial behaviour; the SDQ also gives a 'total difficulties score' (TDS), which, along with the prosocial score, indicates strengths such as positive social skills and general resilience.

It is critical to consider the cultural sensitivity of tools used for psychological testing (Birbili, 2000), especially when the population studied is different from the one in which the test was validated (Balaban, 2006). The SDQ is a brief yet comprehensive measure of a child's sociopsychological adjustment. Its factor structure, reliability and validity, sensitivity and specificity, 